\title{
CVD diamond growth on germanium for IR window applications
}

\author{
C. A. Rego, P. W. May, E. C. Williamson, M. N. R. Ashfold, Q. S. Chia and K. N. Rosser \\ School of Chemistry, University of Bristol, Cantock's Close, Bristol BS8 1TS (UK)
}

N. M. Everitt

Department of Aerospace Engineering, University of Bristol, Unitersity Walk, Bristol BS8 1TR (UK)

\begin{abstract}
We show that the production of adherent polycrystalline diamond films upon Ge substrates by chemical vapour deposition is problematical for three reasons: (a) the melting point of $\mathrm{Ge}$ is close to the optimum diamond deposition temperature which leads to partial melting of the Ge surface, retarding diamond nucleation, (b) there is no Ge carbide layer formed at the interface to bond the diamond to the Ge chemically and (c) there is a large thermal expansion mismatch between diamond and Ge, resulting in cracking and flaking off of the films. Barrier layers of silicon dioxide, nitride or amorphous Si $1 \mu \mathrm{m}$ thick prevent the Ge surface melting, but do not alleviate the expansion mismatch problem. The resulting three-layer sandwich crazes upon cooling, with the delamination occurring at the Ge--barrier interface.
\end{abstract}

\section{Introduction}

The discovery of a means to produce thin films of diamond by chemical vapour deposition (CVD) $[1,2]$ has opened the door to many potential applications, including semiconducting devices, hard wear-resistant coatings and optical components [3,4]. CVD diamond can be used as a free-standing window for IR optics $[5$, 6], however, this requires the diamond film to be of the order of millimetres in thickness, which at typical CVD growth rates requires prohibitively long deposition times. An alternative is to coat existing IR window materials, such as $\mathrm{ZnS}[7], \mathrm{ZnSe}$ or Ge, with a thin layer of CVD diamond, thus protecting the surface from damage without adversely affecting the IR transmission properties.

In this paper we focus on single-crystal $\mathrm{Ge}$, which is often used as an IR window for laser applications, since it has excellent transmission in the range $2-20 \mu \mathrm{m}$. Unfortunately, however, $\mathrm{Ge}$ suffers from the disadvantage of being brittle and prone to scratching, and it is usual, therefore, to coat Ge windows with a hard film to protect the surface. Diamond-like carbon (DLC) films have been previously used for this purpose [2], but CVD diamond also possesses the correct properties for such a layer, so long as it can be deposited reliably and reproducibly onto $\mathrm{Ge}$. This provides the motivation for the present study, which is a preliminary investigation to assess CVD diamond $\mathrm{Ge}$ compatibility.

\section{Experimental details}

Diamond deposition was performed in a hot-filament reactor operating under standard CVD growth conditions [1]. A 1 vol. \% methane in hydrogen gas mixture was admitted to the reactor at a total flow rate of 200 standard $\mathrm{cm}^{3} \mathrm{~min}^{-1}$ and a pressure of 30 Torr. A Ta filament at a temperature of $2000{ }^{\circ} \mathrm{C}$ was used to activate the gas mixture, causing diamond to deposit onto the substrate. The deposition rate was about $0.5 \mu \mathrm{m} \mathrm{h}^{-1}$.

The substrates used were (a) single-crystal $\mathrm{Si}$ with epitaxial layers of $\mathrm{Si}-\mathrm{Ge}$ alloy $2 \mu \mathrm{m}$ thick, the $\mathrm{Ge}$ contents being specifically $13,25,30,60$ and 100 at. $\%$, (b) single-crystal $\mathrm{Ge}$ (random orientation) and (c) singlecrystal $\mathrm{Ge}$ with plasma-deposited barrier layers. The barrier layers were $1 \mu \mathrm{m}$ thick, and were made from amorphous $\mathrm{Si}$, silicon dioxide or silicon nitride. All substrates were polished with $1-3 \mu \mathrm{m}$ diamond grit prior to diamond deposition, with care being taken not to abrade away any delicate barrier layers.

Analysis of the deposited diamond films was performed using scanning electron microscopy and transmission electron microscopy (TEM). Laser Raman spectroscopy was used to characterize the quality of the deposited diamond.

\section{Results}

The results will be presented for each type of substrate in turn. 


\section{1. $2 \mu \mathrm{m} \mathrm{Si-Ge} \mathrm{layers} \mathrm{on} \mathrm{Si}$}

As the percentage of $\mathrm{Ge}$ in the layer increased from 0 to 100 at. $\%$ we found that the deposited diamond films became less adherent. Figure 1 shows a cross-section through the substrate for a 100 at. \% Ge layer, highlighting a very jagged diamond-Ge interface containing many voids. This flawed interface results in very poor adhesion and facile delamination of the diamond. In contrast, for layers containing more than $40 \mathrm{at} \% \mathrm{Si}$ (Fig. 2), the quality of the interface is improved and adherence greatly increased. This is thought to be due to the formation of a localized layer of silicon carbide at the boundary which acts as the "glue" bonding the diamond film to the surface.

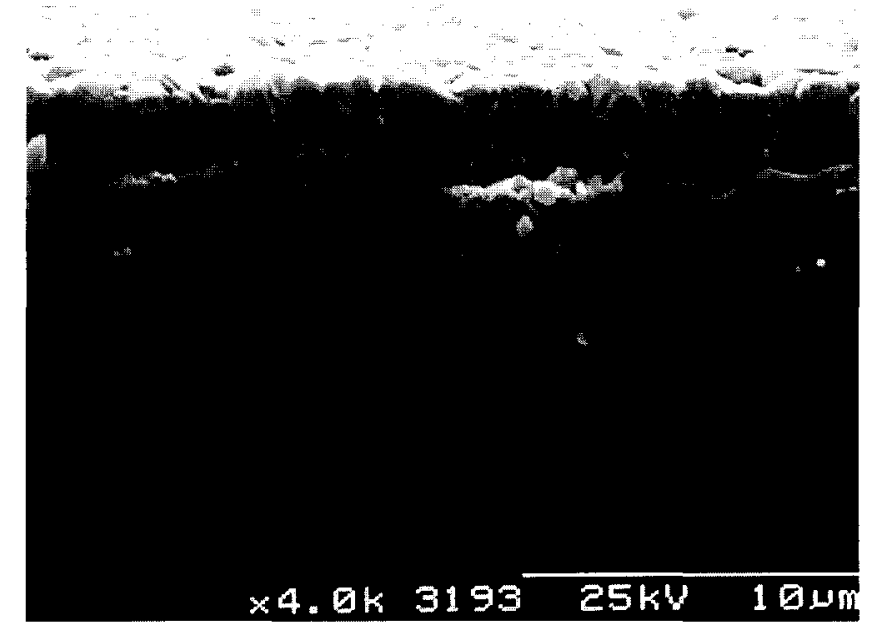

Fig. 1. Electron micrograph of the cross-section through a CVD diamond layer deposited onto a 100 at. $\%$ Ge barrier layer $2 \mu \mathrm{m}$ thick on a $\mathrm{Si}$ substrate. The interface between the diamond and $\mathrm{Ge}$ is jagged, and many holes and voids can be seen.

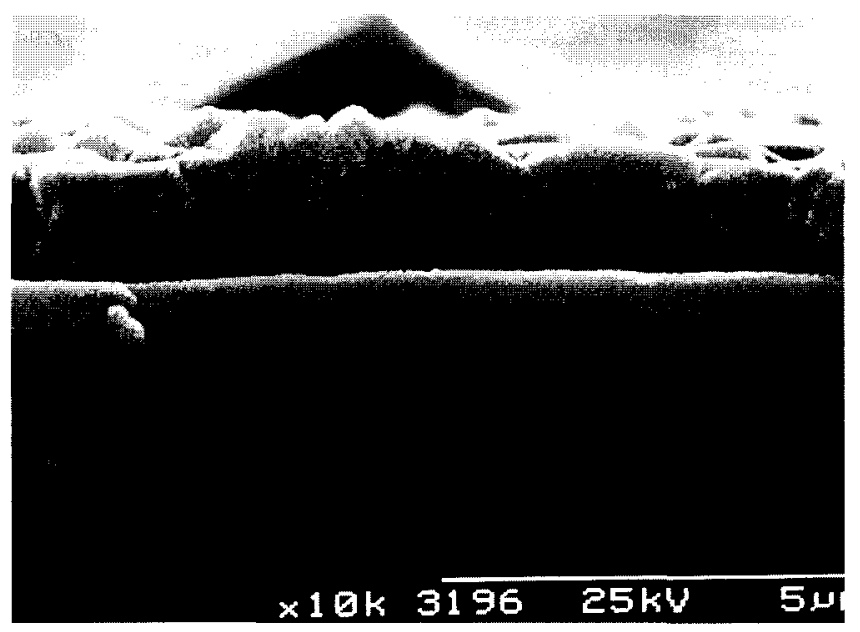

Fig. 2. Cross-section similar to that in Fig. 1, except the barrier layer here was an alloy containing 40 at. $\% \mathrm{Ge}-60$ at. $\% \mathrm{Si}$. The presence of $\mathrm{Si}$ has greatly improved the interface, and the diamond film is now strongly adherent.

\subsection{Single-crystal Ge}

There are three main problems associated with growing diamond on Ge. First, the melting point of $\mathrm{Ge}$ $\left(937^{\circ} \mathrm{C}\right)$ is very close to the deposition temperature of about $900^{\circ} \mathrm{C}$. This leads to partial melting of small areas of the Ge surface, hindering diamond nucleation. The effect can be seen in Fig. 3, which shows a diamondcoated region adjacent to a region where the Ge surface melted. This partial melting of the surface was not observed for the 100 at.\% Ge layer on $\mathrm{Si}$ in Section 3.1, since the bulk Si substrate acted as an efficient heat sink, lowering the local surface temperature below the melting point of Ge.

The second problem is that Ge does not form any solid carbides, although they are known in gaseous form $[8,9]$. TEM and electron energy loss spectroscopy analysis of the interfacial region confirmed the absence of any carbide layer between the Ge and diamond. The lack of any strong chemical bonding between the diamond and Ge leads to poor adhesion and hence flaking off of the film.

Adhesion is further impaired by the mismatch in thermal expansion between diamond and $\mathrm{Ge}\left(1 \times 10^{-6} \mathrm{~K}^{-1}\right.$ and $5.9 \times 10^{-6} \mathrm{~K}^{-1}$ respectively at $300 \mathrm{~K}$, and $4.4 \times 10^{-6} \mathrm{~K}^{-1}$ and $8.5 \times 10^{-6} \mathrm{~K}^{-1}$ respectively at $1000 \mathrm{~K}[10])$. Growing diamond at lower temperatures (below $700{ }^{\circ} \mathrm{C}$ ) eliminated the problems of Ge surface melting, but at the expense of a greatly reduced deposition rate and films with higher graphite content. These films also suffered from poor adherence and delaminated.

\subsection{Barrier layers on Ge}

Various barrier layers were used in an attempt to alleviate some of the problems of growing diamond directly upon $\mathrm{Ge}$. Barriers made from silicon-based materials (amorphous $\mathrm{Si}, \mathrm{SiO}_{2}$ and $\mathrm{Si}_{3} \mathrm{~N}_{4}$ ) were chosen

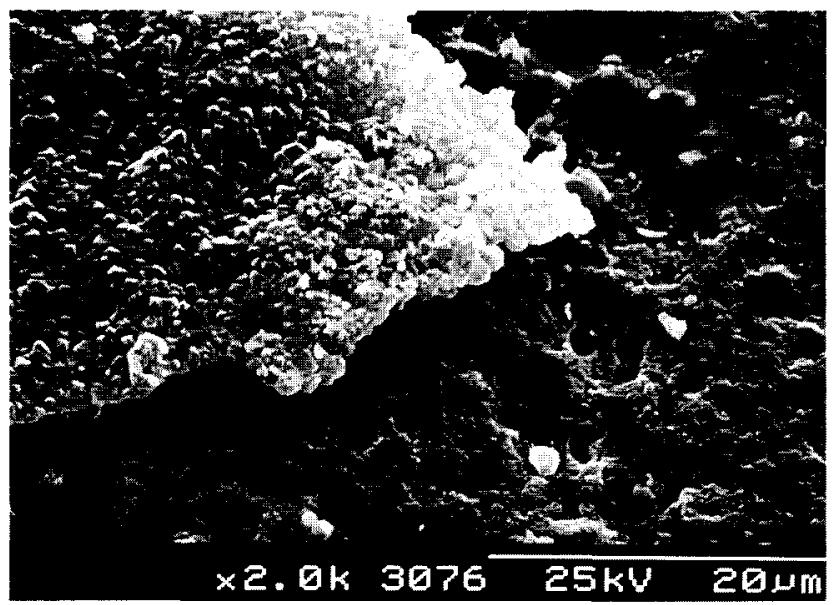

Fig. 3. Electron micrograph of a CVD diamond film deposited on Ge. The film is poorly adherent. Regions of partial melting of the Ge surface can be seen where diamond has not nucleated. 
since the carbide-forming properties of $\mathrm{Si}$ should help adherence. Also, since $\mathrm{SiC}$ has a thermal expansion coefficient between that of $\mathrm{Ge}$ and diamond $\left(2.9 \times 10^{-6} \mathrm{~K}^{-1}\right.$ at $300 \mathrm{~K}$ and $5.0 \times 10^{-6} \mathrm{~K}^{-1}$ at $1000 \mathrm{~K}$ [10]), any interface containing $\mathrm{SiC}$ may act as a stressrelieving layer. Furthermore, the Si layer, with its higher melting point $\left(1410^{\circ} \mathrm{C}\right)$, acts as a thermal barrier, preventing the underlying Ge from melting. These benefits all increase with increasing thickness of the Si layer, but unfortunately $\mathrm{Si}$ is only poorly transmitting in the IR [11], and so the thickness of the Si barrier must be kept to a minimum if the final multilayer sandwich is to be used as an IR window [12].

The results for all the barrier layers were disappointing. Although they acted as good thermal barriers preventing the Ge from melting and so enabling the growth of uniform polycrystalline diamond, the diamond films invariably cracked and flaked off owing to the compressive stresses produced upon cooling. The delamination occurred from the interface between the barrier layer and the $\mathrm{Ge}$, rather than the barrier and diamond. Thinner layers of amorphous $\mathrm{Si}(4 \mathrm{~nm}$ and $0.5 \mu \mathrm{m})$ were also used to reduce the effect of stress, but these were not sufficiently thick to prevent the Ge surface melting.

\section{Conclusions}

Unless a suitable barrier layer is found which will increase the adherence of the diamond films without causing cracking or impairing IR transmission, it seems unlikely that diamond can be used as a hard wearresistant coating for Ge IR windows.

\section{Acknowledgments}

We would like to thank the Department of Trade and Industry for financial support, and S.T.S., Newport, Gwent, for depositing the barrier layers. P.W.M. also thanks the Ramsay Memorial Trust and British Gas for funding. Published with the permission of the Controller of Her Majesty's Stationery Office.

\section{References}

1 F. G. Celii and J. E. Butler, Annu. Rev. Phys. Chem., 42 (1991) 643.

2 A. H. Lettington and J. W. Steeds (eds.), Philos. Trans. R. Soc. London, Ser. A, 342 (1993) 193.

3 P. K. Bachmann, D. Leers and D. U. Wiechert, Ber. Bunsenges. Phys. Chem., 95 (1991) 1390.

4 J. C. Angus, Thin Solid Films, 216 (1992) 126.

5 X. X. Bi, P. C. Eklund, J. G. Zhang and A. M. Rao, J. Mater. Res. 5 (1990) 811

6 M. A. Akerman, J. R. McNeely and R. E. Clausing, Proc. Soc. Photo-Opt. Instrum. Eng., 1325 (1990) 178.

7 T. Hartnett, R. Miller, D. Montanari, C. Willingham and R. Tustison, J. Vac. Sci. Technol. A, 8 (1990) 2129.

8 J. Drowart, G. de Maria, A. J. H. Boerboom and M. G. Inghram, J. Chem. Phys., 30 (1959) 308.

9 R. W. Olesinski and G. J. Abbaschian, Bull. Alloy Phase Diagrams, 5 (1984).

10 Y. S. Touloukian, R. K. Kirby, R. E. Taylor and T. Y. R. Lee (eds.), Thermophysical Properties of Matter-Non-Metallic Solids, Vols. 12 and 13 IFI-Plenum, New York, 1977.

11 Infra-red Materials Data Handbook, B.D.H. Crystran Crystals, Poole, Dorset, 1988.

12 M. B. Tzolov, N. V. Tzenov and D. I. Dimova-Malinovska, J. Phys. $D, 26(1993) 111$ 